\title{
Climate change effects on winter chill for tree crops with chilling requirements on the Arabian Peninsula
}

\author{
Eike Luedeling • Jens Gebauer • Andreas Buerkert
}

Received: 19 May 2008 / Accepted: 16 December 2008 / Published online: 10 April 2009

(C) The Author(s) 2009. This article is published with open access at Springerlink.com

\begin{abstract}
Fruit production systems that rely on winter chill for breaking of dormancy might be vulnerable to climatic change. We investigated decreases in the number of winter chilling hours $\left(0-7.2^{\circ} \mathrm{C}\right)$ in four mountain oases of Oman, a marginal area for the production of fruit trees with chilling requirements. Winter chill was calculated from long-term hourly temperature records. These were generated based on the correlation of hourly temperature measurements in the oases with daylength and daily minimum and maximum temperatures recorded at a nearby weather station. Winter chill was estimated for historic temperature records between 1983 and 2008, as well as for three sets of synthetic 100-year weather records, generated to represent historic conditions, and climatic changes likely to occur within the next 30 years (temperatures elevated by $1^{\circ} \mathrm{C}$ and $2^{\circ} \mathrm{C}$ ). Our analysis detected a decrease in the numbers of chilling hours in high-elevation oases by an average of 1.2-9.5 h/year between 1983 and 2008, a period during which, according to the scenario analysis, winter chill was sufficient for most important species in most years in the highest oasis. In the two climate change scenarios, pomegranates, the most important tree crop, received insufficient chilling in $13 \%$ and $75 \%$ of years, respectively. While production of most traditional fruit trees is marginal today, with trees barely fulfilling their chilling requirements, such production might become impossible in the near future. Similar developments are likely to affect other fruit production regions around the world.
\end{abstract}

E. Luedeling · J. Gebauer · A. Buerkert

Organic Plant Production and Agroecosystems Research in the Tropics and Subtropics, Institute of Crop Science, University of Kassel, Steinstr. 19, 37213 Witzenhausen, Germany

E. Luedeling $(\bowtie)$

Department of Plant Sciences,

University of California Davis, 3015 Wickson Hall, One Shields Ave, Davis, CA 95616, USA

e-mail: eluedeling@ucdavis.edu, tropcrops@uni-kassel.de 


\section{Introduction}

In recent years, much research has been devoted to estimating the implications of climate change for agricultural production (Hanratty and Stefan 1998; Liverman et al. 1986; Lobell et al. 2006; Schneider 1977; Walker and Schulze 2008). Field crops in particular have received considerable attention, with most research scenarios including a doubling of the atmospheric carbon dioxide concentration (Bertrand et al. 2007; Kim et al. 2007; Marhan et al. 2008) and/or a temperature increase by $2^{\circ} \mathrm{C}$ or more (Estrella et al. 2007; Krishnan et al. 2007; Xiao et al. 2007), reflecting the most likely future climate estimates proposed by the Intergovernmental Panel on Climate Change (IPCC 2007) and other climate modeling efforts. Field crops, such as maize (Zea mays L.), wheat (Triticum aestivum L.) and rice (Oryza sativa L.) are by far the largest contributors to meeting the food energy demands of a growing human population. While the challenges in producing sufficient amounts of these crops in the future will be enormous, they may not be the most susceptible to climate change, since the production of annual field crops in a climatically altered world will be aided by the relative mobility of such crops. Relocating plantations of perennial tree crops, in contrast, is much more difficult, because of the longterm investments involved in such enterprises. Moreover, the pattern of climatic dependency of fruit crops is much more complex than that of most annuals. While in annual crops, adjustments to climatic changes can be relatively easily implemented, e.g. by shifts in the planting and harvest dates, many perennials require a certain climatic regime in both the winter and the summer seasons, making such simple approaches to adaptation infeasible.

One of the major determinants of good yields in many fruit trees is the availability of winter chill. Trees and shrubs that require winter chill rely on the occurrence of cold conditions during the winter, in order to break their dormancy and initiate fructification. In spite of the importance of this phenomenon for horticultural production, the physiological details of this process are still relatively unknown, and the existence of several competing models to quantify winter chill suggests that the climatic conditions required to break a tree's dormancy are as yet relatively poorly understood and possibly vary between species (Kozlowski and Pallardy 2002; Rea and Eccel 2006). This is also reflected by the fairly elaborate structure of some existing models and by their specificity to a certain species or even variety (Richardson et al. 1974; Shaltout and Unrath 1983). Several authors suggest that a species' chilling requirement is not necessarily fulfilled by a certain number of hours below a given temperature threshold. Warm temperatures might instead compensate for earlier chilling hours (Lüdders and Wernke 2003; Shaltout and Unrath 1983), or the breaking of dormancy might happen in two phases (Erez and Couvillon 1987). The easiest and most common approach to approximating winter chill conditions, however, is to sum up the seasonal hours between $0^{\circ} \mathrm{C}$ and $7.2^{\circ} \mathrm{C}$ (Bennett 1949 ; Weinberger 1950). Since this approach is widely used in practical horticultural production, and for most fruit species, chilling requirements are typically given as hours within this range, it seems to be the most appropriate approximation of chilling conditions, allowing the widest possible conclusions.

In subtropical fruit growing regions, where chilling-sensitive crops are cultivated, chilling conditions occur during the coldest hours of the day during the winter. 
Such regions can thus be expected to react strongly to increases in daily minimum temperatures during the cold season. Several recent modeling efforts and longterm temperature observations have indicated that much of the recently observed global warming trend can be attributed to rising minimum temperatures, which have increased at a faster rate than mean or maximum temperatures (Easterling et al. 1997; Lobell et al. 2007; Vincent et al. 2005; Vose et al. 2005; Zhang et al. 2005; Zheng et al. 1997). Perennial fruit production systems, which are long-term operations that depend on seasonally low temperatures, may thus be among the agricultural or horticultural systems that are most vulnerable to climate change (Blanke 2008; Cannell et al. 1989; Seguin 2003). In a recent study, Baldocchi and Wong (2008) have investigated trends in chilling conditions in California, finding a pronounced decrease in the number of chilling hours at most sites. While they expect these changes to have deleterious consequences by the end of the twenty-first century, other regions might feel detrimental effects of reduced winter chill at a much earlier date.

An ideal site for studying the effects of climatic changes on fruit production systems that receive marginal winter chill is the high-mountain region of Al Jabal al Akhdar in the Sultanate of Oman (Scholz 1984; Gebauer et al. 2007). Almost the entire area of this desert country lies at low elevation at subtropical and tropical latitudes, with mean annual temperatures ranging between 25 and $30^{\circ} \mathrm{C}$, peak summer temperatures exceeding $45^{\circ} \mathrm{C}$ and virtually no hours of temperatures below $7.2^{\circ} \mathrm{C}$ during the winter (Fisher 1994). Fruit production systems in the lowlands are thus composed of species that do not have a chilling requirement, such as date palm (Phoenix dactylifera L.), mango (Mangifera indica L.), papaya (Carica papaya L.) and lime (Citrus aurantiifolia (L.) Swingle). At higher altitudes, however, a small number of mountain oases at elevations of up to 2,000 $\mathrm{m}$ above sea level, cultivate a different assemblage of crops (Buerkert et al. 2005; Gebauer et al. 2007; Luedeling and Buerkert 2008a, b). Farmers in these ancient cropping systems grow pomegranates (Punica granatum L.), peaches (Prunus persica L.), apricots (Prunus armeniaca L.), walnuts (Juglans regia L.), and even apples (Malus domestica Borkh.), pears (Pyrus communis L.) and plums (Prunus domestica L.), all of which have minimum chilling requirements between 100 and $400 \mathrm{~h}$ (Table 1) and thus cannot be found in the lowlands. In spite of the relative favorability of these locations, with a reliable water supply and cool winter seasons, yields of some of the cultivated fruits have been low in recent years in some of the oases, including almost complete crop failures of peaches and apricots in several years. While low yields can have many causes, the locations of these oases in an area of marginal winter chill merits an investigation of the altitudinal and temporal dynamics of winter chill in this region. The presence of mountain oases along a long elevation gradient, stretching over more than 1,000 m, and the presence of a long-term weather station in this region provide an excellent setting for analyzing the effects of climatic changes on the prevalence of chilling conditions in a region of marginal winter chill.

The potential implications of this study extend well beyond the oasis farming systems of Oman. In many parts of the world, fruit growers use winter chill models to identify appropriate tree cultivars for their production sites. This practice is common in most subtropical growing regions, such as Israel (Erez et al. 1979), South Africa (Linsley-Noakes and Allan 1994), Spain (Ruiz et al. 2007) and California (Baldocchi and Wong 2008). Growers in these regions generally know very well how much 
Table 1 List of all fruit species found in the four studied oases of Al Jabal al Akhdar, northern Oman in 2006

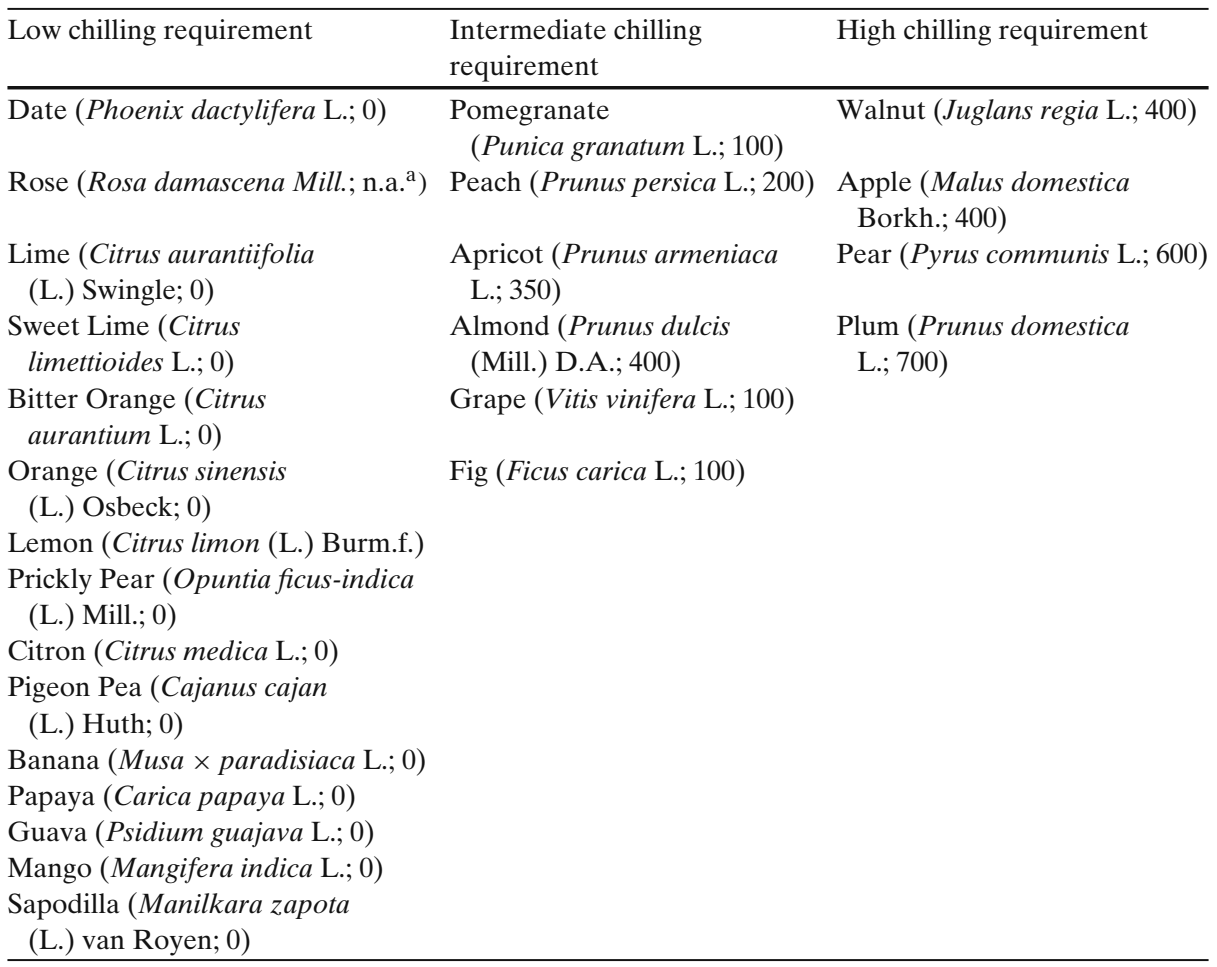

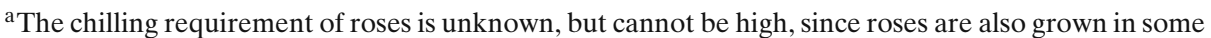
oases at much lower altitude. Numbers in parentheses indicate the minimum chilling requirement for the species according to Noel (2007) and Baldocchi and Wong (2008)

winter chill they can expect in the majority of years and select their crops accordingly. Information about historic levels of winter chill is derived from experience, reflecting conditions of the recent past, whereas the potentially productive years of the cultivars that are selected based on this information in most cases extend decades into the future. In times of rising temperatures in most growing regions, it is possible that for many species and varieties selected in such a process, winter chill conditions will become marginal by the time the trees reach their physiological bearing age. While the Omani oases might be among the most marginal areas for the production of fruit and nut trees with chilling requirements today, many other regions may be similarly marginal for the species and varieties that were selected or bred for past chilling regimes. In terms of winter chill conditions, the oasis systems that are the subject of this study are thus representative of traditional and non-traditional farming systems around the world that include perennial crops with chilling requirements. Our study will therefore provide important information about the challenges that climatic changes, expected to occur within the next few decades, are likely to present to such cropping systems. 


\section{Materials and methods}

\subsection{Study sites}

The study was conducted in four mountain oases along an elevation gradient in $\mathrm{Al}$ Jabal al Akhdar, Sultanate of Oman (Fig. 1). These oases were Masayrat ar Ruwajah at 1,030-1,060 m.a.s.l., Salut (1,430-1,450 m.a.s.l.), Qasha' (1,620-1,640 m.a.s.l.) and a contiguous agricultural area surrounding the oases of $\mathrm{Al}$ 'Ayn, Al 'Aqr and Ash Sharayjah (referred to only as Al 'Ayn in the following; 1,750-1,930 m.a.s.l.).

For Masayrat ar Ruwajah, Qasha' and Al 'Ayn, aerial photographs were taken using a remotely-operated model plane equipped with a digital camera (Schäper 2006). All images were georeferenced using a differential GPS (Pathfinder ProXRS, Trimble Navigation Ltd., Sunnyvale, CA, USA) and rectified using ERDAS IMAGINE 8.5 (Leica Geosystems GIS \& Mapping LLC., Norcross, GA, USA).

\subsection{Tree counts}

Based on the aerial images, all cultivated fruit trees and perennial shrubs of all oases were counted in the field, classified according to species and entered into a Geographical Information System, using ArcMap 9.2 (ESRI Inc., Redlands, CA, USA). For Salut, no aerial photograph was available because the village was too far away from the take-off sites of the plane at Al 'Ayn and Masayrat ar Ruwajah. The gardens of Salut are, however, relatively small and the tree count could be done without an image for orientation. For mapping purposes, the location and shape of Salut's gardens were sketched using a satellite image downloaded from Google Earth (Google, Mountain View, CA, USA), which was georeferenced by the location of the other oases. For each tree species, the minimum number of chilling hours that is required for complete breaking of dormancy was extracted from the Australian Tree Crops Sourcebook (Noel 2007), and all trees were classified into species with (1) low chilling requirement $\left(<100 \mathrm{~h}\right.$ of between $0^{\circ} \mathrm{C}$ and $\left.7.2^{\circ} \mathrm{C}\right),(2)$ intermediate chilling requirement $(100-300 \mathrm{~h})$ and $(3)$ high chilling requirement $(>300 \mathrm{~h})$. This rough classification was necessary, because no information exists on the actual chilling requirements of the traditional Omani cultivars.

\subsection{Temperature measurements}

For collection of weather data, HOBO Pro climate loggers (Onset Computer Corp., Pocasset, MA, USA) were installed in the gardens of Al 'Ayn, Qasha' and Masayrat ar Ruwajah. These loggers recorded temperatures at half-hourly intervals between 21 February 2005 and 9 April 2008 at Al 'Ayn (with one period of missing data between April and July of 2007), from 19 April 2005 to 9 April 2008 at Qasha' (with periods of missing data between April and September of 2006 and April and May 2007) and between 7 March 2005 and 13 April 2008 at Masayrat ar Ruwajah. Loggers were placed in standard wooden boxes designed for weather stations and positioned $1.5 \mathrm{~m}$ above terraces cropped with alfalfa (Al 'Ayn and Masayrat ar Ruwajah) or annual fodder grass (Qasha').

To allow a long-term assessment of chilling conditions in the oases, additional weather data were taken from an official weather station at Saiq (World 

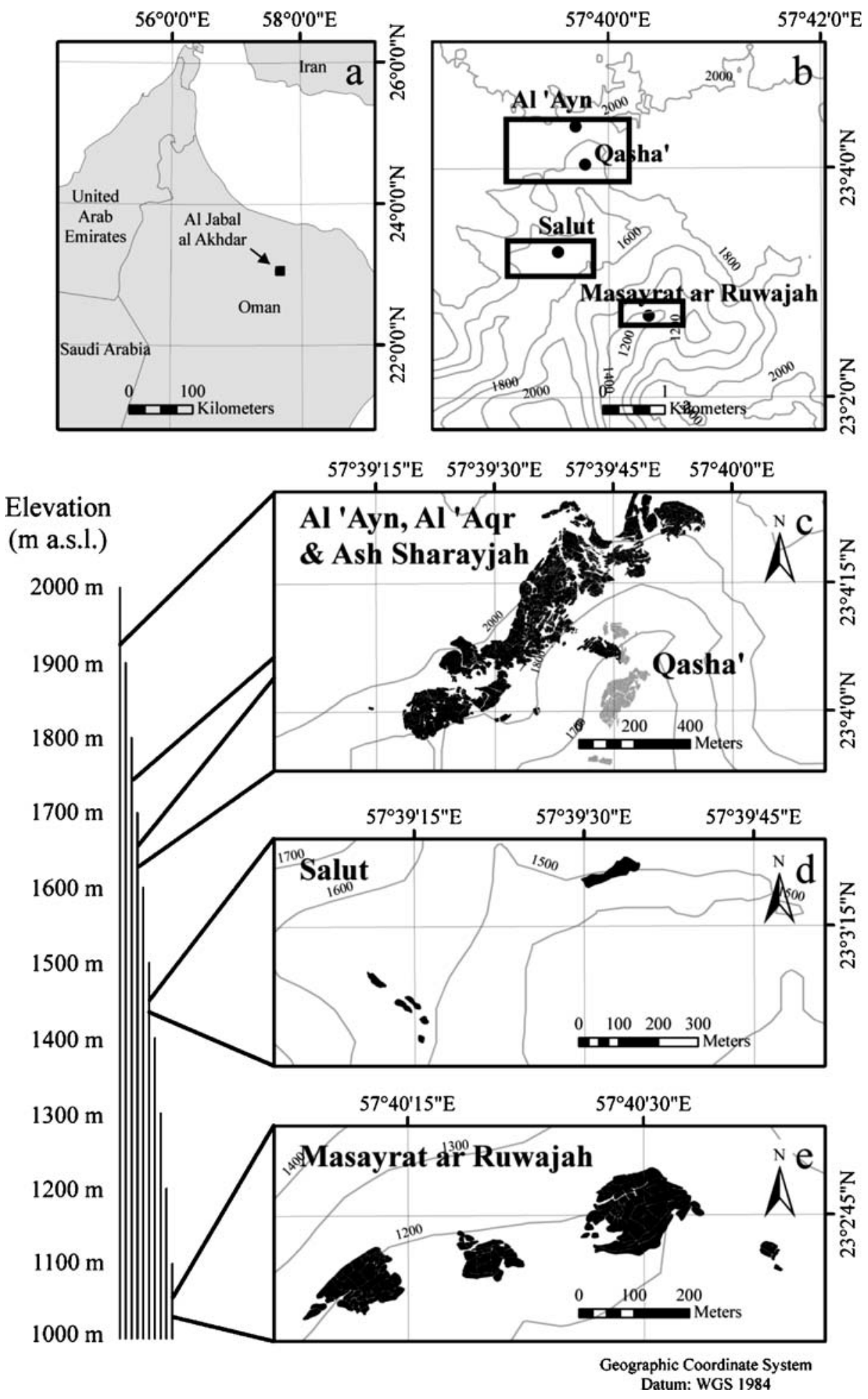
Fig. 1 Maps showing the location of Al Jabal al Akhdar on the Arabian Peninsula (a), the locations of the study oases in Al Jabal al Akhdar (b) and the fields of Al 'Ayn, Qasha' (c, fields drawn in black belong to Al 'Ayn, gray areas to Qasha'), Salut (d) and Masayrat ar Ruwajah (e) and their position in the context of the elevation gradient

Meteorological Station No. 412540), which is located only a few kilometers from the study area at an altitude of approximately 1,950 m.a.s.l. Hourly temperature measurements from this station between 1 January 2004 and 31 July 2007 were obtained from the Directorate General of Civil Aviation and Meteorology, Muscat, Oman. Linear regressions between this dataset and the data collected in the oases revealed that the Saiq temperature records are a reliable proxy for the temperatures in our study oases (Fig. 2). Hourly temperature records from this weather station are only available since 2004, when the station's equipment was modernized, whereas the station's record of daily values goes back to 1979 . The full dataset of daily records was obtained from the National Climatic Data Center (NCDC 2008) of the US National Oceanic and Atmospheric Administration (NOAA). Since the dataset contained several gaps, missing values of minimum, mean and maximum temperatures were interpolated linearly from temperatures measured on days before and after the gaps. Winter seasons, during which more than 50 days were missing between November and April, were excluded from further analysis. This was the case for the winters of $1979 / 1980$ to $1982 / 1983,1984 / 1985$, and $1988 / 1990$ to $1990 / 1991$ (Fig. 3).

\subsection{Temperature modeling}

In order to estimate chilling conditions in the past, we used our measurements in the oases and the high-resolution record from Saiq to calibrate the long-term record of daily temperatures. For such an analysis to be meaningful, the consistency of the long-term record must first be ensured. Especially the record of mean temperatures deserves scrutiny, since daily mean temperatures can be determined by one of three methods. The most accurate method, which is being applied at the station since 2004,

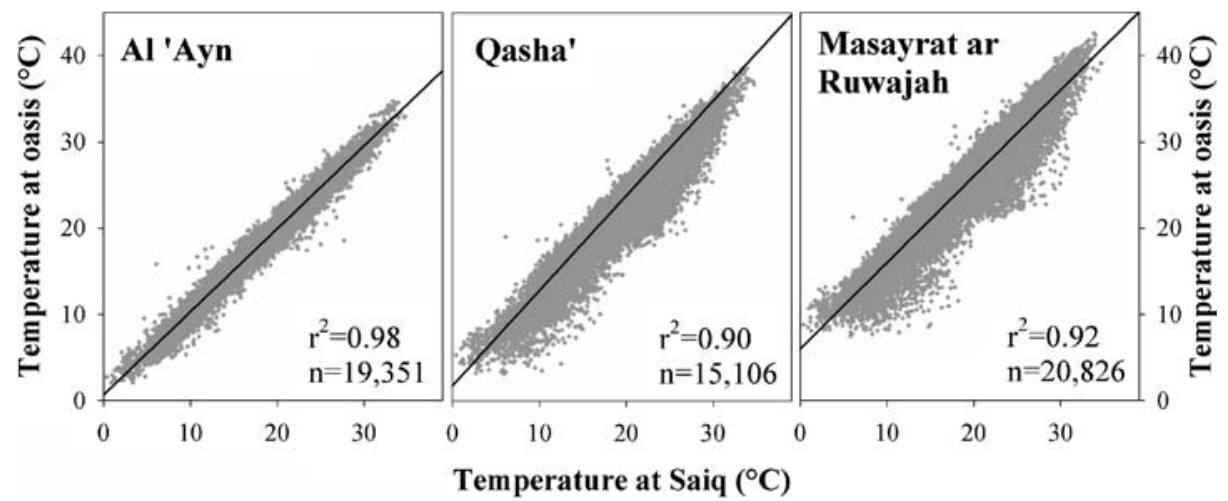

Fig. 2 Linear regressions between the hourly temperatures recorded at Saiq between 2004 and 2007 and hourly averages of all temperatures measured at the oases of Al 'Ayn, Qasha' and Masayrat ar Ruwajah during parts of this time span 
Fig. 3 Gaps in the NCDC record of minimum daily temperatures measured at Saiq, summarized by winter seasons ranging from November of one year to April of the following year. The black line indicates the threshold that led to a year's exclusion from analysis of chilling hours

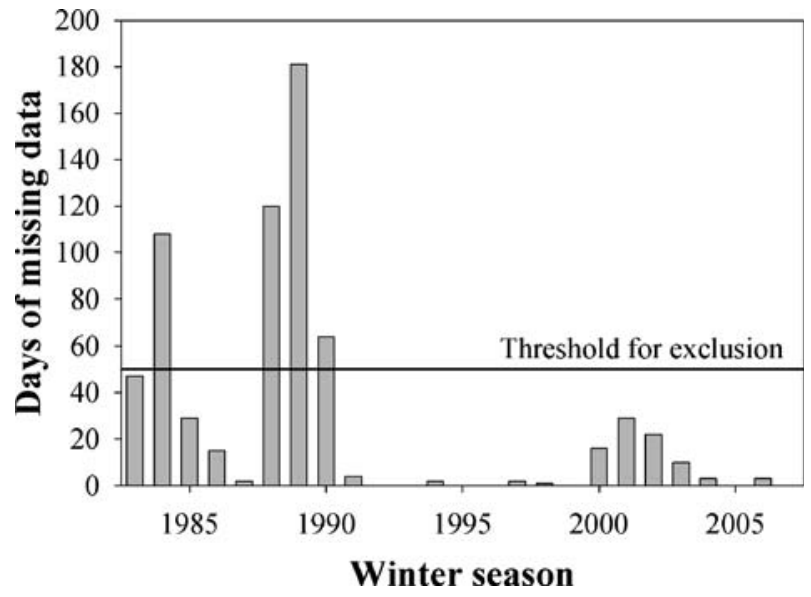

is to record temperatures at hourly or even higher resolution and arithmetically average all temperatures measured during a given day. In the absence of high-resolution measurements, however, mean temperatures are typically derived by calculating the mean between minimum and maximum temperatures, which can be determined at much higher accuracy with a simple minimum-maximum thermometer, or they are based on point measurements at a certain time of day. A good indicator of which method was used for calculating mean temperatures, and of possible changes in the calculation technique, is the location of the mean temperature $\left(T_{\text {mean }}\right)$ relative to the maximum $\left(T_{\max }\right)$ and minimum $\left(T_{\min }\right)$ temperatures. This measure can be expressed by the ratio $R$ of the difference between maximum and mean temperature and the difference between mean and minimum temperature:

$R=\frac{T_{\max }-T_{\operatorname{mean}}}{T_{\operatorname{mean}}-T_{\min }}$. In the absence of major shifts in the diurnal temperature curves, this ratio should remain relatively unchanged over long periods of time. For the station at Saiq, the ratio shifted substantially over time, in particular from 2003 to 2004, indicating that the mean temperatures recorded here are not useful for detecting long-term climatic trends (Fig. 4). In contrast, minimum and maximum temperatures

Fig. 4 Ratio of the difference between maximum and mean temperature and between mean and minimum temperature $\left(\left(T_{\text {max }}-T_{\text {mean }}\right)\right)$ $\left.\left(T_{\text {mean }}-T_{\min }\right)\right)$ for the long-term temperature record from Saiq, given as monthly averages. Separate linear regressions were calculated for the periods before and after the modernization of the measuring equipment in 2004, indicating a shift in the procedure used to calculate the mean temperature

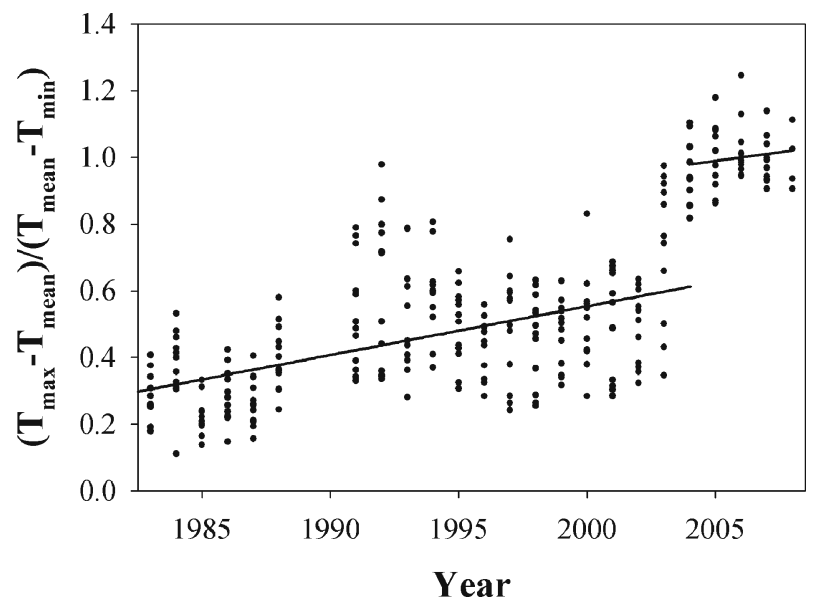



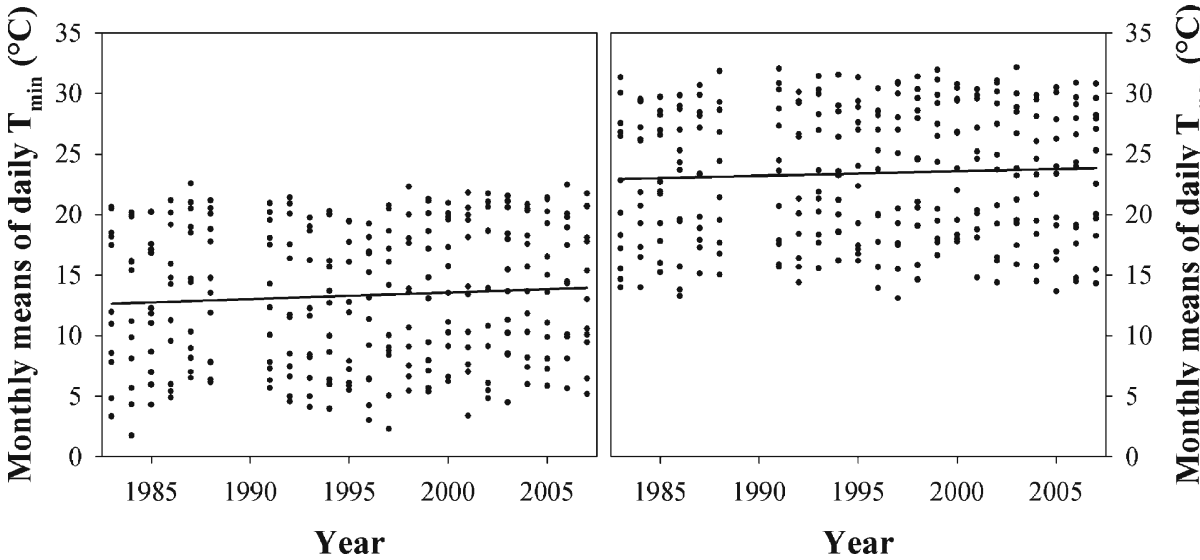

Fig. 5 Monthly means of daily minimum temperature $\left(T_{\min } ; l e f t\right)$ and maximum temperature $\left(T_{\max }\right.$; right) recorded at the weather station in Saiq since 1983. The lines result from a linear regression over the whole dataset

were apparently not affected by methodological changes (Fig. 5). Both mean monthly $T_{\min }$ and $T_{\max }$ show a steady but statistically insignificant increase by $0.05^{\circ} \mathrm{C} \mathrm{a}^{-1}$ for $T_{\min }(p=0.25)$ and $0.03^{\circ} \mathrm{C} \mathrm{a}^{-1}$ for $T_{\max }(p=0.45)$. For individual months, however, warming trends were significant, mainly affecting the winter months of November, January and February, when chilling is most likely to occur (Table 2). Based on these findings about the quality of the weather data, we used only the minimum and maximum daily temperatures for modeling hourly temperatures. Since the daily curve of hourly temperatures is influenced by the time of year, the daylength as modeled by Jarmo Lammi's sunrise/sunset/daylength calculator (downloaded on April 16th, 2008 from http://www.geocities.com/jjlammi/) was included as an additional parameter to account for different sunrise and sunset times during the

Table 2 Trends in monthly means of daily minimum and maximum temperatures observed at Sayq, Oman between 1979 and 2008, adjusted coefficient of determination $\left(R^{2}\right)$ of the linear regression equations and probability that the data do not contain a significant trend $(p)$

\begin{tabular}{llllllll}
\hline Month & \multicolumn{2}{l}{ Minimum temperature } & & \multicolumn{3}{l}{ Maximum temperature } \\
\cline { 2 - 3 } \cline { 6 - 7 } & Slope $\left({ }^{\circ} \mathrm{C} \mathrm{a}^{-1}\right)$ & $R^{2}$ adjusted & $P$ value & & Slope $\left({ }^{\circ} \mathrm{C} \mathrm{a}^{-1}\right)$ & $R^{2}$ adjusted & $P$ value \\
\hline January & +0.07 & 0.13 & $0.04^{\mathrm{a}}$ & +0.02 & -0.03 & 0.58 \\
February & +0.09 & 0.24 & $0.01^{\mathrm{a}}$ & +0.08 & 0.17 & $0.03^{\mathrm{a}}$ \\
March & +0.02 & -0.02 & 0.50 & +0.03 & -0.01 & 0.40 \\
April & +0.07 & 0.08 & 0.09 & +0.08 & 0.07 & 0.11 \\
May & +0.04 & -0.01 & 0.39 & +0.05 & 0.07 & 0.12 \\
June & +0.03 & -0.02 & 0.50 & -0.01 & -0.04 & 0.80 \\
July & +0.05 & 0.17 & $0.03^{\mathrm{a}}$ & +0.03 & 0.02 & 0.25 \\
August & +0.04 & 0.09 & 0.09 & +0.07 & 0.22 & $0.01^{\mathrm{a}}$ \\
September & +0.05 & 0.07 & 0.11 & & +0.03 & 0.03 & 0.21 \\
October & +0.05 & 0.10 & 0.08 & +0.04 & 0.05 & 0.17 \\
November & +0.09 & 0.30 & $0.00^{\mathrm{a}}$ & +0.02 & -0.03 & 0.52 \\
December & +0.05 & 0.02 & 0.24 & -0.03 & -0.01 & 0.42 \\
\hline
\end{tabular}

${ }^{\mathrm{a}}$ Trend is statistically significant at $p<0.05$ 
course of the year. This tool calculates the daily sunlight hours for a given date based on a location's latitude.

For each oasis, we then determined a prediction equation for hourly temperatures based on daily minimum and maximum temperatures and daylength, using the Partial Least Squares (PLS) regression procedure in JMP 7 (SAS Institute Inc., Cary, NC, USA) to derive the model coefficients. For determining the number of latent factors to be included in the regression, we used the program's cross-validation procedure. Separate regressions were carried out for each hour of the day ( 0 through 23) and for each of the three oases.

The resulting regression equations were used to estimate the temperatures for each hour since 1979 based on the long-term record of daily minimum and maximum temperatures from Saiq and the daylength for each day of the year. From the modeled hourly temperatures and the elevations of Masayrat ar Ruwajah and Qasha', we interpolated hourly temperatures for Salut, which lies at an intermediate altitude. In the resulting temperature record for all four oases, we then classified each hour, for which modeled temperatures were between $0^{\circ} \mathrm{C}$ and $7.2^{\circ} \mathrm{C}$ as a chilling hour, and summed up the number of chilling hours for each winter season (November to April) that had less than 50 days of missing data.

\subsection{Present and future chilling scenarios}

Analyzing time series allows only limited conclusions about the long-term risks of severe consequences of climate change, because every year of the record is affected by interannual climate variation. Extremely warm or cool years in a time series might be improbable outliers rather than true representatives of long-term trends. This limitation of time series can be overcome by generating synthetic long-term weather records, which are representative of conditions during one selected year. In this procedure, the statistical characteristics of long-term weather records are determined, and a large number of representative years is generated based on these characteristics. A random seed is used to introduce variability into the record. Such synthetic temperature records can then be analyzed statistically, yielding valuable information about the likelihood that a certain climatic variable will exceed or fall short of a given threshold value in a given year.

We used the LARS-WG stochastic weather generator (Semenov 2008) to generate three synthetic weather records. These records represented temperature conditions observed at Saiq between 1979 and 2008, as well as two climate change scenarios, in which mean monthly minimum and maximum temperatures were elevated by $1{ }^{\circ} \mathrm{C}$ and $2{ }^{\circ} \mathrm{C}$, respectively. These estimates are in the range of temperature projections by the Intergovernmental Panel on Climate Change (IPCC 2007) between 1980-1999 and 2020-2029. Since the 'present' scenario represents the median year of the historic record (1994) and temperatures appear to be increasing by about $0.05^{\circ} \mathrm{C}$ annually, the two future scenarios can be interpreted as representing climatic conditions around 2014 and 2034.

As input for the weather generator, we used all daily measurements of minimum and maximum temperatures and rainfall recorded at Saiq. Since the software also required measurements of solar radiation, we added such data recorded at the town of Sayh Qatanah, about $2 \mathrm{~km}$ from the weather station, between 2005 and 2006 (Luedeling and Buerkert 2008a). For all three scenarios, we generated 100 years of 
daily weather data. From these daily estimates, we then modeled hourly temperatures based on the PLS regression equations and calculated annual chilling hours as described above.

\section{Results}

\subsection{Tree count}

In the terraces around $\mathrm{Al}$ 'Ayn, we found 22 species of tree and shrub crops with a total of 10,346 individual plants, the highest numbers of all oases studied. Qasha' followed with 21 species (1,358 individuals), whereas the gardens of Salut (14 species, 425 individuals) and Masayrat ar Ruwajah (12 species, 1457 individuals) were substantially less diverse. The dominant species in the three upper oases was pomegranate, followed by rose (Rosa damascena Mill.) in Al 'Ayn and peach in Qasha' and Salut. In Masayrat ar Ruwajah, the upper story of the vegetation was dominated by date palm, followed by banana (Musa $\times$ paradisiaca L.). According to Noel (2007, published online only, refer to Baldocchi and Wong 2008 for a published version of the table), 15 tree or shrub species had minimum chilling requirements of less than $100 \mathrm{~h}$, six species ranged between 100 and $300 \mathrm{~h}$, and four species had chilling requirements of more than $300 \mathrm{~h}$ (Table 1). While these numbers might indicate that the oases are not very sensitive to chilling conditions, the distribution of individual trees and shrubs among chilling requirement classes leads to different conclusions. Since pomegranates and peaches made up between $60 \%$ and $80 \%$ of the trees at Al 'Ayn, Salut and Qasha', the majority of trees cultivated here had intermediate chilling requirements. Trees with even higher chilling requirements, walnuts and apricots in particular, made up 5\% of the trees at $\mathrm{Al}$ 'Ayn, and 4\% at Qasha' and Salut (Fig. 6).

\subsection{High-resolution temperature measurements and model development}

Mean annual temperatures calculated from measurements in the oases were $18.6^{\circ} \mathrm{C}$ for $\mathrm{Al}$ 'Ayn, $20.8^{\circ} \mathrm{C}$ for Qasha' and $24.7^{\circ} \mathrm{C}$ for Masayrat ar Ruwajah, with the temperature ranging from $-2.6^{\circ} \mathrm{C}$ to $34.8^{\circ} \mathrm{C}$ at $\mathrm{Al}$ 'Ayn, from $0.3^{\circ} \mathrm{C}$ to $38.8^{\circ} \mathrm{C}$ at

Fig. 6 Proportion of tree and shrub specimens having chilling requirements of $<100$, 100-300 and $>300 \mathrm{~h}$ at the four oases studied. Roses were classified in the class of lowest chilling requirement

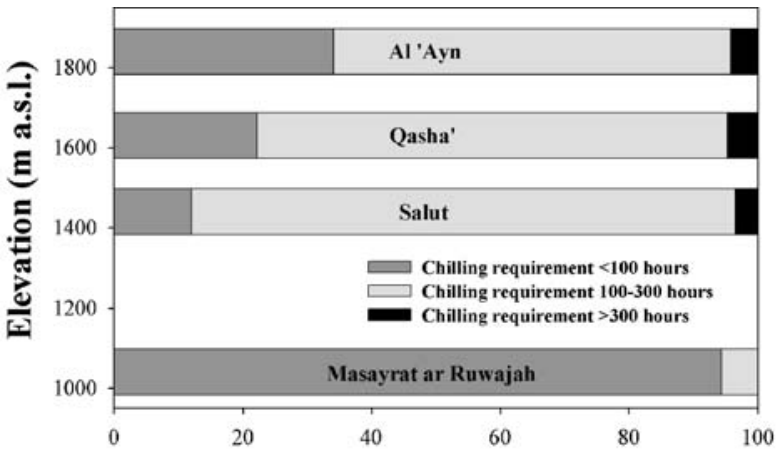

Cumulative share of all trees and shrubs at oasis (\%) 
Qasha' and from $5.8^{\circ} \mathrm{C}$ to $42.8^{\circ} \mathrm{C}$ at Masayrat ar Ruwajah. In the long-term record from Saiq, daily minimum temperatures varied between $-3.6^{\circ} \mathrm{C}$ and $29^{\circ} \mathrm{C}$, with a mean daily minimum of $12.8^{\circ} \mathrm{C}$, whereas daily maximum temperatures ranged between $7.3^{\circ} \mathrm{C}$ and $44^{\circ} \mathrm{C}$, with a mean of $23^{\circ} \mathrm{C}$. Modeled daylength varied between 10.62 and $13.45 \mathrm{~h}$.

The models for predicting hourly oasis temperatures, derived by Partial Least Squares regression, yielded very good fits for all $24 \mathrm{~h}$ of the day at all three oases (72 regressions in total). Model coefficients varied substantially throughout the day at all oases, with nighttime temperatures being highly and positively correlated with minimum temperatures, whereas during the afternoon, the correlation with the maximum temperature was closer and more positive (Fig. 7). The model coefficients for the daylength were more variable. While their distribution was mostly even throughout the day, they exhibited two pronounced peaks at each oasis (Fig. 7).

\subsection{Long-term temperature and chilling modeling}

Hourly temperatures were modeled separately for each oasis and hour of the day based on the equation $T_{\text {modeled }}=\mathrm{PLS}_{\text {intercept }}+\left(T_{\min } \mathrm{PLS}_{\min }\right)+\left(T_{\max } \mathrm{PLS}_{\max }\right)+$ (DL PLS Daylength $_{\text {, with }}$ PLS min $_{\text {m }}$, PLS $_{\max }$ and PLS Daylength $_{\text {being the PLS model }}$ coefficients shown in Fig. 7 and PLS intercept $_{\text {the }}$-axis intercept of the PLS regression equation for the respective hour. $T_{\min }, T_{\max }$ and DL are the measured or modeled minimum or maximum temperatures or daylengths for the respective oasis.

Fig. 7 Model coefficients of the prediction model for hourly temperatures at the oases of Al 'Ayn, Qasha' and Masayrat ar Ruwajah, based on daylength (solid lines), minimum temperature $\left(T_{\min }\right.$, short dashes) and maximum temperature $\left(T_{\max }\right.$, long dashes) at Saiq

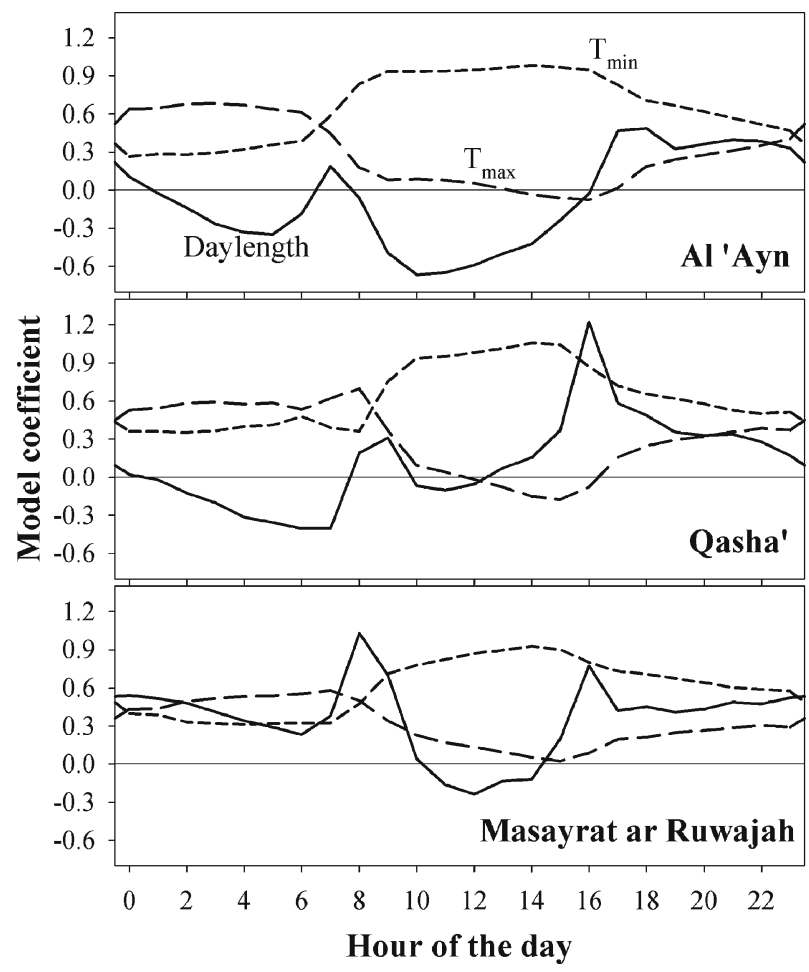

Hour of the day 


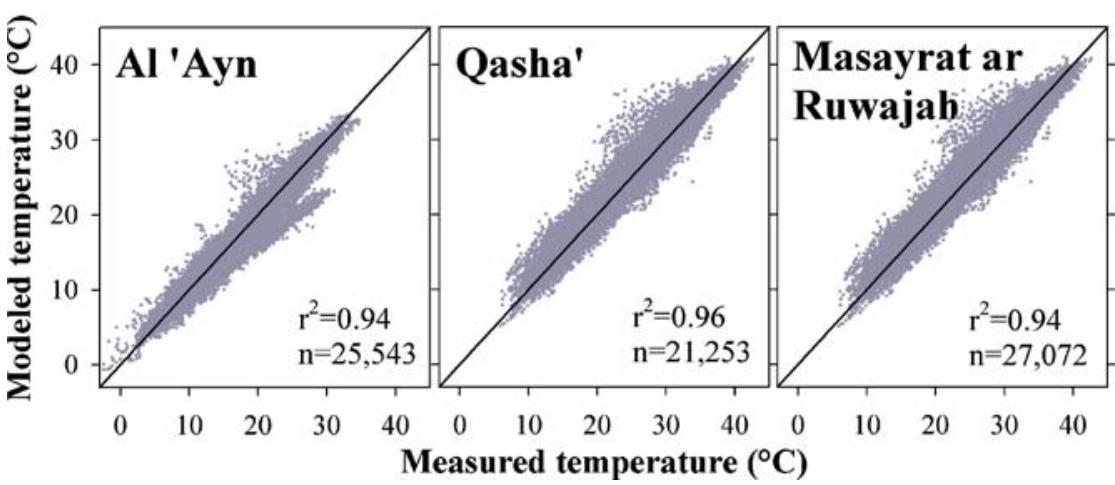

Fig. 8 Linear regression between temperatures measured in the oases of Al 'Ayn, Qasha' and Masayrat ar Ruwajah and temperatures modeled from daylength and minimum and maximum temperatures at Saiq. The black lines indicate identity $(\mathrm{x}=\mathrm{y})$

For the time period, for which modeled and measured temperatures were available, these two datasets were quite similar (Fig. 8). Coefficients of determination of linear regressions between modeled and measured temperatures were higher than 0.94 for all oases, and the probability of lack of fit to identity between the datasets was lower than 0.0001 . These numbers indicate that the modeling procedure was useful for estimating temperature conditions in the oases. The annual numbers of chilling hours for the historic record were then estimated based on the modeled high-resolution temperature record (Fig. 9). For Al 'Ayn, the season with the largest number of chilling hours was the winter of $1983 / 1984$ with $615 \mathrm{~h}$ between $0^{\circ} \mathrm{C}$ and $7.2^{\circ}$ C. Also at Qasha' $(287 \mathrm{~h})$ and Salut $(114 \mathrm{~h})$, the highest numbers of chilling hours were recorded during this winter. The lowest numbers of chilling hours occurred at Al 'Ayn in the winter of 1999/2000 (166 h), while at Qasha' the previous winter (1998/1999) had the fewest chilling hours (48 h). At Salut, both of these winters had only three chilling hours, the lowest on the record. At Masayrat ar Ruwajah, chilling

Fig. 9 Estimated numbers of chilling hours at the oases of Al 'Ayn, Qasha', Salut and Masayrat ar Ruwajah during winters between 1983 and 2008. The dashes in the figure indicate years that had too many missing data to be included in the analysis. Lines indicate linear regressions. For Masayrat ar Ruwajah, this line is almost identical with the abscissa, whereas for all other oases, the mean annual increments are indicated in the graph

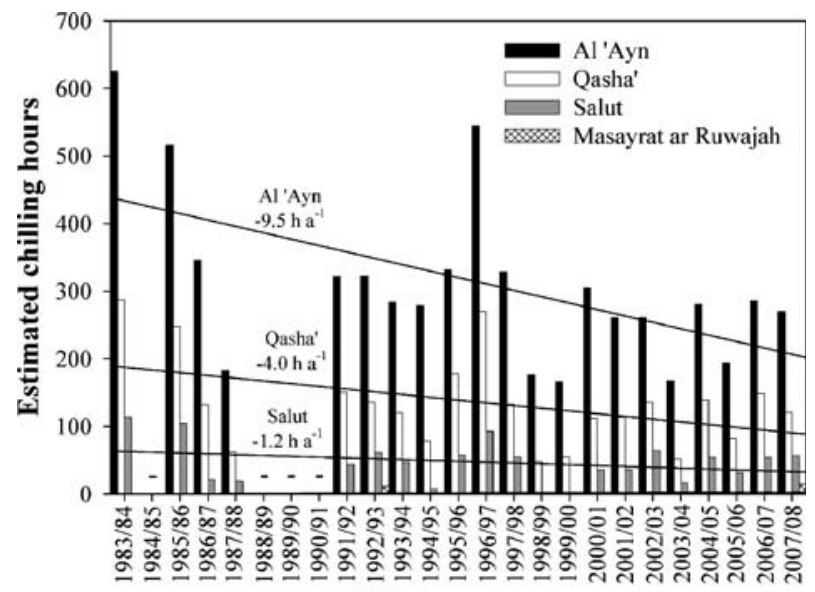

Winter season 
conditions occurred rarely, with the winters of 1992/1993 and 2007/2008 having 12 and $15 \mathrm{~h}$ between $0^{\circ} \mathrm{C}$ and $7.2^{\circ} \mathrm{C}$, respectively, whereas during all other years, no more than three chilling hours were recorded (Fig. 9). Linear regression of winter chill over the whole record indicated that the number of chilling hours declined significantly $(p<0.01)$ by an average of $9.5 \mathrm{~h} / \mathrm{year}$ at $\mathrm{Al}$ 'Ayn, by $4.0 \mathrm{~h}$ at Qasha' (not statistically significant; $p=0.05)$ and by $1.2 \mathrm{~h}$ at Salut $(p=0.20)$. The slight increasing trend at Masayrat ar Ruwajah $(+0.1$ per year; $p=0.32)$ was insignificant (Fig. 9).

\subsection{Present and future chilling scenarios}

In the winter chill distribution calculated from the synthetic 100 -year weather record representing present conditions (Fig. 10), winter chill exceeded 400 chilling hours, representative of the requirements of low-chill walnuts, in only $5 \%$ of all years. The minimum requirement for apricots, $350 \mathrm{~h}$, was exceeded in 19 out of 100 modeled years. For these two crops, which presently make up only $3 \%$ of all trees, winter chill appeared insufficient for optimal production in most years. For peaches, which constitute $4 \%$ of tree specimens, winter chill was above the minimum requirement $(200 \mathrm{~h})$ in $85 \%$ of modeled years, whereas the main crop, pomegranates $(57 \%$ of trees, chilling requirement of $100 \mathrm{~h}$ ), never received insufficient chilling. Mean winter chill in this scenario was 274 chilling hours (Fig. 10).

For the first future scenario (Historic record $+1^{\circ} \mathrm{C}$ ), mean winter chill was only 156 chilling hours. Minimum chilling requirements of walnuts were never met in this scenario, while apricots received enough chilling in only 1 year. Unlike in the 'present' scenario, chilling appeared insufficient for the more common trees in

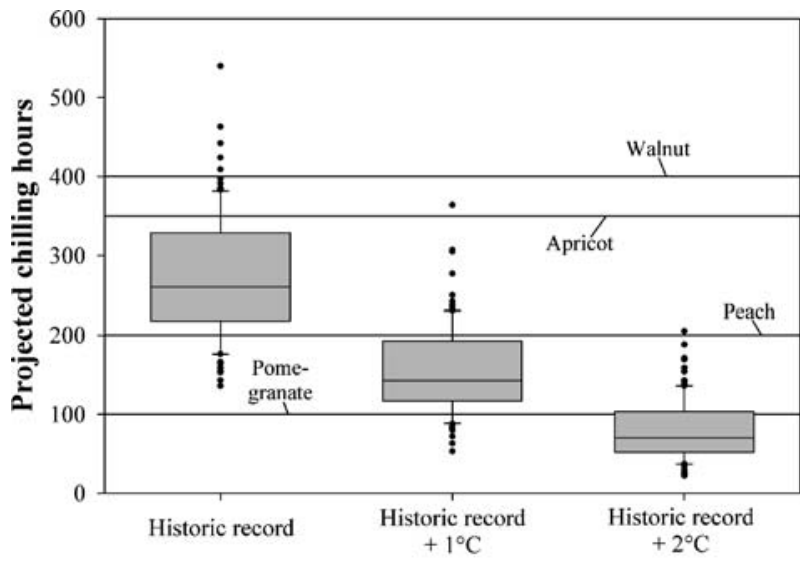

Climate scenario

Fig. 10 Distributions of the numbers of chilling hours derived from synthetic 100-year weather records for $\mathrm{Al}$ 'Ayn, Oman, representing the historic record, as well as two climate change scenarios (Historic record $+1^{\circ} \mathrm{C}$ and Historic record $+2^{\circ} \mathrm{C}$ ). The horizontal lines indicate the minimum chilling requirements of walnuts, apricots, peaches and pomegranates, some of the main crops of this oasis. In box plots, the central line indicates the median of the distribution, the edges of the box are the $25 \%$ and $75 \%$ quantiles, the error bars are the $10 \%$ and $90 \%$ quantiles, and all outliers beyond these limits are marked by dots 
many years, with minimum requirements for peaches met in only $23 \%$ of years, and even pomegranates not receiving enough chilling in 13 years of the 100 -year record (Fig. 10).

When temperatures were increased by $2^{\circ} \mathrm{C}$ (Historic record $+2^{\circ} \mathrm{C}$ ), only 1 year supplied enough chilling for peaches, and even the low requirement of 100 chilling hours for pomegranates was not met in $75 \%$ of years on the record. Mean winter chill in this scenario was 80 chilling hours.

\section{Discussion}

\subsection{Tree count}

The fruit tree assemblage at the four oases clearly reflected the climatic conditions at each site, and appeared to be correlated to the prevalence of chilling conditions (Fig. 6). The proportion of trees with chilling requirements above $300 \mathrm{~h}$ was highest at Al 'Ayn and Qasha', lower at Salut and zero at Masayrat ar Ruwajah, where such requirements would never be met. The intermediate fraction (chilling requirements between 100 and $300 \mathrm{~h}$ ) was dominant at the three upper oases and insignificant at Masayrat ar Ruwajah. At the lowest oasis of the gradient, almost all trees had no chilling requirement. The surprising increase in the proportion of perennial crops that do not require chilling temperatures at altitudes above Salut was caused by an increasing number of rose bushes at higher altitude, where the petals of these shrubs are used for making rose water. We classified roses as low-chill crops, because we observed rose cultivation at much lower altitudes, but it is not unlikely that cool temperatures are necessary to obtain a high quality crop. We are, however, not aware of any studies on this issue, which is why roses were assigned to the lowest chilling class.

From the results of our chilling hour model, we assumed that the production of crops with intermediate or high chilling requirements at Salut and Qasha' has always entailed the risk of low yields or even crop failure in years with warm winters. Nevertheless, the production of such crops was probably worthwhile for local farmers, since it provided them with several specialty products that were rare in Oman and thus ensured high profits on regional markets. Moreover, many of the lowland crops would not thrive under the cool winter conditions of the high mountains, with especially the occasional occurrence of frost imposing a threat to some of these species.

The low proportion of trees with high chilling requirements at all upper oases suggests that past chilling regimes did not allow the reliable production of crops that needed more than about $400 \mathrm{~h}$ of winter chill, indicating that such cold winters were probably the exception rather than the rule in decades before the start of local weather recording.

\subsection{Temperature modeling}

The procedure for modeling hourly temperatures provided a very good approximation of temperatures, as they were observed during the study period (Fig. 8). Model coefficients for minimum and maximum temperature varied throughout the day, with 
the importance of maximum temperatures increasing after sunrise, and subsequently diminishing after sunset (Fig. 7). The two daily peaks in the relative importance of daylength in the regression model reflect the different topographic settings of the three oases. At Al 'Ayn, the peaks were less pronounced and further from midday than in the other oases. The reason for this is the position of this oasis just below the edge of an extensive mountain plateau. This site is thus relatively little affected by the shadowing effect of the surrounding mountains, which has a pronounced impact on the seasonal variation in the amount of solar radiation that reaches the oases of Qasha' and Masayrat ar Ruwajah, both of which lie at the bottom of deep valleys. Including the daylength as a model factor and modeling temperatures at hourly resolution thus helped capture the topographic variability of the study area.

The very high accuracy of the model fit (Fig. 8) was probably due to the very homogeneous weather conditions in Oman. Considering that no attempt was made to capture the influence of cloudiness, rain or other weather phenomena, the little scatter that remained in the dataset is remarkable. For regions with more diverse weather patterns, such a good model fit can probably not be attained without the inclusion of additional parameters describing cloud cover or comparable variables. Such variables, however, are not typically available in long-term weather records.

\subsection{Observed and projected chilling conditions}

The number of annual winter chilling hours declined at Salut, Qasha' and in particular at Al 'Ayn, with the decline being highly significant at Al 'Ayn and almost significant at Qasha' $(p=0.0508)$. The temperature record was relatively short (1983-2008), however, and thus might not represent the full spectrum of interannual variation. The slight increase in chilling hours at Masayrat ar Ruwajah appears coincidental, since significant amounts of chilling hours only occurred during two years on the entire record. These two occurrences coincided with brief spells of extraordinary cold, leading to rare frost at Al 'Ayn.

Within the time span, for which historic temperatures were recorded, the annual number of chilling hours dropped to levels that seemed to seriously threaten the production of peaches and apricots in Qasha', and are mostly unable to fulfill the reported chilling requirement of pomegranates at Salut. It should be noted, however, that temperatures for Salut were merely interpolated, leaving the possibility for cooler local microclimatic conditions than would be expected by simple interpolation. At Al 'Ayn, the amount of winter chill in recent years seemed insufficient for complete breaking of dormancy in all trees that required more than $400 \mathrm{~h}$ of chilling, such as walnut and apple, while long-term trends appeared to worsen conditions for all tree crops with chilling requirements.

The scenario analysis for the historic record (Fig. 10) showed that the current crop composition at $\mathrm{Al}$ 'Ayn was well adapted to the distribution of winter chill that could be expected. While insufficient chilling for walnuts and apricots seemed very likely in most years, these species made up only a small proportion of tree specimens in the oasis and received relatively little maintenance, so that crop failures were unlikely to be economically consequential. For the more common trees, sufficient winter chill seemed almost guaranteed.

In the two warming scenarios, however, the current crop composition appeared much less suitable for the expected distribution of annual winter chill. If mean daily 
minimum and maximum temperatures rise by $2^{\circ} \mathrm{C}$, farmers at $\mathrm{Al}$ 'Ayn might lose their ability to achieve satisfactory yields of pomegranates, their current economic staple, in most years. These two warming scenarios are not unrealistic. General Circulation Models presented by the IPCC (2007) estimate temperature increases of between 1 and $1.5^{\circ} \mathrm{C}$ over $1980-1999$ temperatures by 2020-2029. For 20902099, these models predict temperature increases between 2 and $4^{\circ} \mathrm{C}$. This indicates that the increasing trends we observed in the historic temperature record (Fig. 2) are likely representative of real changes rather than artifacts of a relatively short temperature record. If temperatures keep increasing at an annual rate of $0.05^{\circ} \mathrm{C}$, the Historic $+1^{\circ} \mathrm{C}$ temperature scenario could become reality around 2014 (20 years after the median date of the historic record), while temperatures could correspond to the Historic $+2^{\circ} \mathrm{C}$ scenario by 2034 .

The decline in the number of chilling hours thus appears to be happening at a rapid pace, with the potential of serious consequences for the traditional cropping pattern of these ancient oasis systems. Within less than 30 years, farmers might be forced to adapt to insufficient winter chill for their most important crops. Potential may lie in the introduction of low-chill cultivars or the application of rest-breaking agents to promote the breaking of dormancy. Given the current marginal conditions for temperate fruit trees and the continuing decrease in winter chill, however, we consider it very likely that much of the traditional production of fruit and nut trees with chilling requirements will soon become impossible in Oman's high-altitude mountain oases.

\section{Conclusions}

Using high-resolution temperature measurements to calibrate long-term lowresolution weather records proved a useful tool for evaluating climate change processes. Modeling winter chill using this technique indicated that high-mountain oases in Oman are marginal sites for the production of fruit species with chilling requirements. If recent warming trends continue over the next few decades, winter chill might become insufficient for the successful cultivation of an increasing proportion of the fruit and nut varieties that have traditionally been grown at these sites. Since the investigated oases are among the highest and thus coldest settlements in Oman, with water resources at higher altitudes being very limited, the traditional land use systems of these ancient oases might soon be forced to undergo major changes in the assemblage of cultivated crops, or face increasing risks of crop failure in the future.

Similar temperature trends throughout the Middle East (Zhang et al. 2005) make it likely that our findings are representative of a regional trend. It can be assumed that other fruit production regions, where similar crop species are grown under marginal chilling conditions, are also susceptible to even slight warming trends. Given the longterm costs and commitments involved in planting and maintaining fruit orchards, systematic studies on how winter chill conditions can be expected to change in the short and medium term will represent invaluable tools for horticultural decisionmaking in the future.

Acknowledgements The cooperation of the farmers of Al 'Ayn, Al 'Aqr, Ash Sharayjah, Qasha', Salut and Masayrat ar Ruwajah is gratefully acknowledged. We are indebted to Uta Dickhoefer for maintaining the temperature loggers in the field, to Sultan Qaboos University in Muscat, Oman, for 
technical support and to the German Research Foundation (DFG) for funding (BU 1308). We also wish to express our gratitude to Dr. Herbert Dietz of the Sultanate of Oman's Royal Court Affairs and to the Directorate General of Civil Aviation and Meteorology for granting us access to their weather records.

Open Access This article is distributed under the terms of the Creative Commons Attribution Noncommercial License which permits any noncommercial use, distribution, and reproduction in any medium, provided the original author(s) and source are credited.

\section{References}

Baldocchi D, Wong S (2008) Accumulated winter chill is decreasing in the fruit growing regions of California. Clim Change 87:S153-S166

Bennett JP (1949) Temperature and bud rest period. Calif Agric 3:9, 12

Bertrand A, Prevost D, Bigras FJ, Lalande R, Tremblay GF, Castonguay Y, Belanger G (2007) Alfalfa response to elevated atmospheric $\mathrm{CO}_{2}$ varies with the symbiotic rhizobial strain. Plant Soil 301:173-187

Blanke MM (2008) Perspectives of fruit research and apple orchard management in Germany in a changing climate. Acta Hort 772:441-446

Buerkert A, Nagieb M, Siebert S, Khan I, Al-Maskri A (2005) Nutrient cycling and field-based partial nutrient balances in two mountain oases of Oman. Field Crops Res 94:149-164

Cannell MGR, Grace J, Booth A (1989) Possible impacts of climatic warming on trees and forests in the United Kingdom - a review. Forestry 62:337-364

Easterling DR, Horton B, Jones PD, Peterson TC, Karl TR, Parker DE, Salinger MJ, Razuvayev V, Plummer N, Jamason P, Folland CK (1997) Maximum and minimum temperature trends for the globe. Science 277:364-367

Erez A, Couvillon GA (1987) Characterization of the influence of moderate temperatures on rest completion in peach. J Am Soc Hortic Sci 112:677-680

Erez A, Couvillon GA, Hendershott CH (1979) Quantitative chilling enhancement and negation in peach buds by high-temperatures in a daily cycle. J Am Soc Hortic Sci 104:536-540

Estrella N, Sparks TH, Menzel A (2007) Trends and temperature response in the phenology of crops in Germany. Glob Chang Biol 13:1737-1747

Fisher M (1994) Another look at the variability of desert climates, using examples from Oman. Glob Ecol Biogeogr Lett 4:79-87

Gebauer J, Luedeling E, Hammer K, Nagieb M, Buerkert A (2007) Mountain oases in northern Oman: An environment for evolution and in situ conservation of plant genetic resources. Genet Resour Crop Evol 54:465-482

Hanratty MP, Stefan HG (1998) Simulating climate change effects in a Minnesota agricultural watershed. J Environ Qual 27:1524-1532

IPCC (2007) Climate change 2007: synthesis report. In: Contribution of working groups I, II and III to the fourth assessment report of the intergovernmental panel on climate change. IPCC, Geneva, p 104

Kim SH, Gitz DC, Sicherb RC, Baker JT, Timlin DJ, Reddy VR (2007) Temperature dependence of growth, development, and photosynthesis in maize under elevated $\mathrm{CO}_{2}$. Environ Exp Bot 61:224-236

Kozlowski TT, Pallardy SG (2002) Acclimation and adaptive responses of woody plants to environmental stresses. Bot Rev 68:270-334

Krishnan P, Swain DK, Bhaskar BC, Nayak SK, Dash RN (2007) Impact of elevated CO2 and temperature on rice yield and methods of adaptation as evaluated by crop simulation studies. Agric Ecosyst Environ 122:233-242

Linsley-Noakes GC, Allan P (1994) Comparison of 2 models for the prediction of rest completion in peaches. Sci Hortic 59:107-113

Liverman DM, Terjung WH, Hayes JT, Mearns LO (1986) Climatic change and grain corn yields in the North-American Great Plains. Clim Change 9:327-347

Lobell DB, Bonfils C, Duffy PB (2007) Climate change uncertainty for daily minimum and maximum temperatures: A model inter-comparison. Geophys Res Lett 34:L05715.1-L05715.5 
Lobell DB, Field CB, Cahill KN, Bonfils C (2006) Impacts of future climate change on California perennial crop yields: Model projections with climate and crop uncertainties. Agric For Meteorol 141:208-218

Lüdders P, Wernke M (2003) Probleme des Kern- und Steinobstanbaus in tropischen Hochlagen Kolumbiens unter besonderer Berücksichtigung des Kältebedürfnisses der Bäume-Problems of pome and stone fruit trees in the highlands of Columbia with special reference to their chilling requirement. Erwerbsobstbau 45:125-134

Luedeling E, Buerkert A (2008a) Effects of land use changes on the hydrological sustainability of mountain oases in northern Oman. Plant Soil 304:1-20

Luedeling E, Buerkert A (2008b) Typology of mountain oases in Oman based on Landsat and SRTM imagery and geological survey data. Remote Sens Environ 113:1181-1195

Marhan S, Derain D, Erbs M, Kuzyakov Y, Fangmeier A, Kandeler E (2008) Soil organic matter mineralization and residue decomposition of spring wheat grown under elevated $\mathrm{CO}_{2}$ atmosphere. Agric Ecosyst Environ 123:63-68

NCDC (2008) Global surface summary of the day data, ver 7. National Climatic Data Center (NCDC) of the National Oceanic and Atmospheric Administration (NOAA), Asheville

Noel D (2007) Australasian tree crops sourcebook. http://www.wanatca.org.au/atcros/LF.htm. Accessed 09 July 2007

Rea R, Eccel E (2006) Phenological models for blooming of apple in a mountainous region. Int J Biometeorol 51:1-16

Richardson EA, Seeley SD, Walker DR (1974) A model for estimating the completion of rest for Redhaven and Elberta peach trees. Hortscience 9:331-332

Ruiz D, Campoy JA, Egea J (2007) Chilling and heat requirements of apricot cultivars for flowering. Environ Exp Bot 61:254-263

Schäper W (2006) Telescopic eyeglasses and model airplanes. In Practice Innovation 17:2-13

Schneider SH (1977) Climate change and world predicament-case-study for interdisciplinary research. Clim Change 1:21-43

Scholz F (1984) Höhensiedlungen am Jabal Akhdar-Tendenz und Probleme der Entwicklung einer peripheren Region im Oman-Gebirge. ZfWG 28:16-30

Seguin B (2003) Adaptation of agricultural production systems to climatic change. C R Geosci 335:569-575

Semenov MA (2008) Simulation of extreme weather events by a stochastic weather generator. Clim Res 35:203-212

Shaltout AD, Unrath CR (1983) Rest completion prediction model for Starkrimson Delicious apples. J Am Soc Hortic Sci 108:957-961

Vincent LA, Peterson TC, Barros VR, Marino MB, Rusticucci M, Carrasco G, Ramirez E, Alves LM, Ambrizzi T, Berlato MA, Grimm AM, Marengo JA, Molion L, Moncunill DF, Rebello E, Anunciacao YMT, Quintana J, Santos JL, Baez J, Coronel G, Garcia J, Trebejo I, Bidegain M, Haylock MR, Karoly D (2005) Observed trends in indices of daily temperature extremes in South America 1960-2000. J Clim 18:5011-5023

Vose RS, Easterling DR, Gleason B (2005) Maximum and minimum temperature trends for the globe: an update. Geophys Res Lett 32:L23822

Walker NJ, Schulze RE (2008) Climate change impacts on agro-ecosystem sustainability across three climate regions in the maize belt of South Africa. Agric Ecosyst Environ 124:114-124

Weinberger JH (1950) Chilling requirements of peach varieties. Proc Am Soc Hortic Sci 56:122-128

Xiao GJ, Zhang Q, Yao YB, Yang SM, Wang RY, Xiong YC, Sun ZJ (2007) Effects of temperature increase on water use and crop yields in a pea-spring wheat-potato rotation. Agric Water Manag 91:86-91

Zhang XB, Aguilar E, Sensoy S, Melkonyan H, Tagiyeva U, Ahmed N, Kutaladze N, Rahimzadeh F, Taghipour A, Hantosh TH, Albert P, Semawi M, Ali MK, Al-Shabibi MHS, Al-Oulan Z, Zatari T, Khelet IA, Hamoud S, Sagir R, Demircan M, Eken M, Adiguzel M, Alexander L, Peterson TC, Wallis T (2005) Trends in Middle East climate extreme indices from 1950 to 2003. J Geophys Res-Atmos 110:D22104

Zheng X, Basher RE, Thompson CS (1997) Trend detection in regional-mean temperature series: maximum, minimum, mean, diurnal range and SST. J Clim 10:317-326 